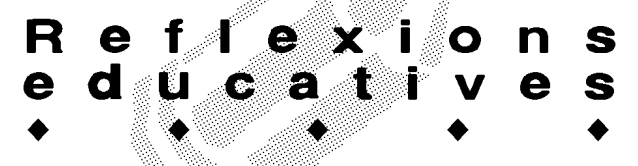

\title{
REPRESENTACIÓ I CONSTRUCCIÓ DE LES NOCIONS CORPORALS, MOTRIUS, ESPACIALS I TEMPORALS A LA SESSIÓ DE PSICOMOTRICITAT
}

\author{
Carme Conde Delgado de Molina. Àrea de Psicologia Evolutiva i de l'Educació. URV \\ Isabel Viscarro Tomàs. Àrea de Didàctica de l'Expressió Corporal. URV
}

\section{Introducció}

Les propostes de treball psicomotriu que s'han fet des de l'anomenada tendència dinàmica, i més concretament des de la proposta de pràctica psicomotriu de B. Aucouturier, coincideixen a diferenciar en les sessions de psicomotricitat dos grans moments: un centrat en el propi cos i el moviment corporal, i un altre centrat en la representació de l'activitat motriu feta al primer moment. S'entén, doncs, que el treball a la sala de psicomotricitat ha d'anar més enllà de l'activitat pròpiament motriu (moviment corporal) i ha d'incloure també l'activitat representativa (representació del moviment corporal). Per aquesta raó l'estructura de les sessions contempla, a més a més del ritual d'entrada i de sortida, un moment d'activitat motriu i un moment de representació (Esquema 1).

Tot i que des de la tendència dinàmica es destaca la importància del moment de representació, es constata la manca d'estudis aprofundits al voltant d'aquesta qüestió, així com d'instruments i recursos per afavorir-la i per fer un seguiment sistemàtic dels progressos en l'activitat representativa dels infants. Aquest va ser un dels motius principals que ens va impulsar a constituir un grup de treball de psicomotricitat, amb la finalitat d'estudiar l'evolució de la representació del propi cos i del moviment, i la relació entre el desenvolupament de les capacitats representatives i la construcció de les nocions corporals, motrius, espacials i temporals al llarg de l'etapa d'Educació Infantil i primer cicle de Primària. Des del curs 2000-01, data en què es va constituir el grup amb el suport de l'Institut de Ciències de l'Educació de la Universitat Rovira i Virgili, estem duent endavant aquesta recerca, de la qual tot seguit expliquen el seu plantejament, objectius, metodologia i estat actual.

L'activitat representativa a la sala de psicomotricitat

L'observació de l'activitat a la sala de psicomotricitat permet identificar quelcom tan obvi com que, en el transcurs de la sessions, els nens i les nenes fan una intensa activitat motriu (salten, corren, s'arrosseguen,

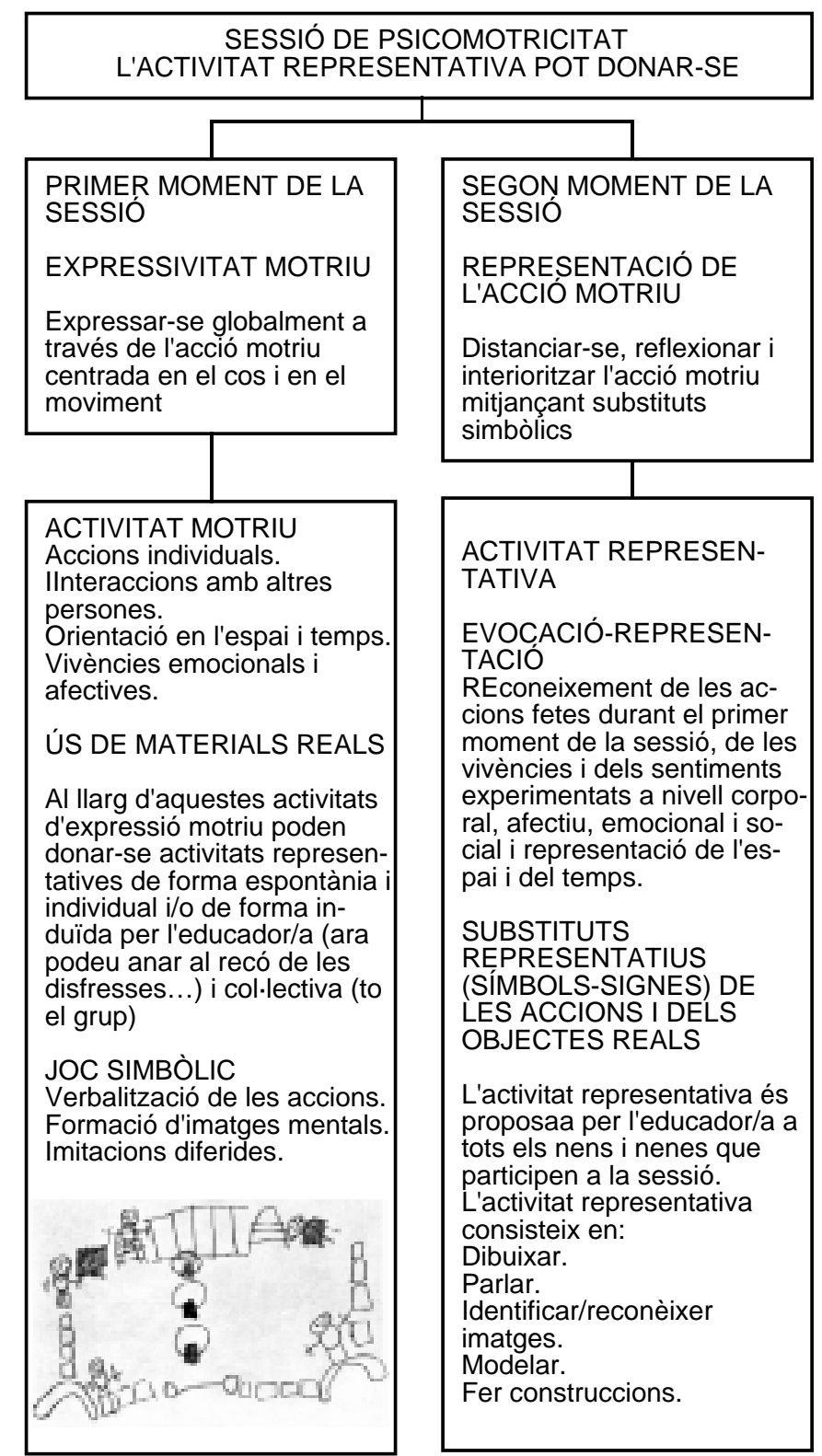

Esquema 1. Estructura de la sessió de psicomotricitat 


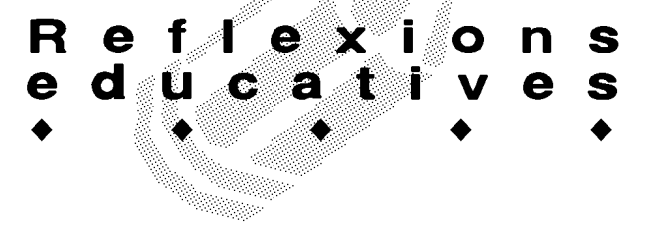

pugen, baixen, es balancegen, s'ajupen, entren dins de, surten de...), que vivencien de forma emocional i afectiva i que implica una interacció constant amb altres nens i nenes i amb l'educador/a. Podríem dir que al llarg d'aquestes sessions els infants s'expressen globalment a través de l'acció motriu, és a dir, a través del cos i de l'activitat corporal manifesten tot allò que saben fer a nivell motriu, tot allò que senten a propòsit d' aquesta activitat (emocions, sentiments) i totes les capacitats relacionals que posen en joc per dur-la endavant (demanar ajuda a l'altre, compartir l'activitat amb l'altre, ajudar l'altre, planificar l'activitat amb l'altre...).

Però també és cert -tot i que això no és, en principi, tan observable com l'activitat motriu, emocional i social abans esmentada-, que en el transcurs del moment d'expressivitat motriu els infants fan una altra mena d'activitat: fan joc simbòlic, potser expliquen al company l'activitat motriu que acaben de fer, fan imitacions diferides d'accions que han vist fer als altres i, en conseqüència, fan evocacions de les imatges mentals que tenen d'aquestes accions, elaboren i retenen imatges mentals d'accions fetes, de les parts del cos emprades en la realització de l'acció... Totes aquestes activitats tenen quelcom en comú: són activitats representatives fetes de forma espontánia pels mateixos infants, que desvetllen el desenvolupament de la capacitat per manejar, entendre i construir representacions de la realitat. Aquesta capacitat s'anomena funció representativa o simbòlica, i la seva aparició al voltant dels 18/24 mesos i el seu desenvolupament al llarg dels anys següents constitueix un dels fets més significatius del desenvolupament psicològic dels infants que es troben en aquestes edats.

La funció representativa és una capacitat específicament humana que permet a les persones emprar símbols i signes per evocar (fer presents) objectes, persones, situacions i experiències absents o no directament perceptibles (referents). Explicar una vivència del passat mitjançant signes lingüístics (Ilenguatge oral o escrit) i gràfics (dibuixos), evocar la imatge mental que un té d'algun objecte o ésser viu (per exemple, d'un elefant), imitar les accions característiques de la vida quotidiana i dels personatges de ficció (imitació diferida) o fer servir una corda com si fos una mànega (joc simbòlic) són manifestacions de la funció representativa. En tots els casos, representem la realitat mitjançant alguna cosa (signe o símbol) que està en el lloc de l'objecte real. Quan representem la realitat, recuperem, fem present, actualitzem allò d'una altra manera (imaginant-la, esmentant-la amb una paraula, dibuixant-la...) i allò que posem en lloc de l'objecte real (la paraula, el dibuix...) ens permet actuar com si aquest estigués present. La representació és una activitat cognitiva d'alt nivell i, com s'ha dit abans, una capacitat específica de les persones (organismes capaços d'entendre i manipular representacions)

Els diversos mecanismes de representació no fan aquesta funció de la mateixa manera:

- Alguns representen la realitat segons un codi analògic (hi ha una relació de semblança entre l'objecte real i allò que posem en el seu lloc. Per exemple, la imatge mental d'un ànec representa aquest animal perquè conté els trets distintius i específics d'aquest animal -un bec, plomes, potes palmípedes, unes determinades dimensions, forma i color...-. La imatge mental de l'ànec representa aquest animal perquè s'asembla a ell; en cas que no s'asemblés, no seria una representació vàlida de l'animal i, per tant, no el representaria. Aquests elements que representen el referent segons un codi analògic s'anomenen símbols. La imatge mental, la imitació diferida, el dibuix i el joc simbòlic són representacions d'aquest tipus, és a dir, són simbols que representen la realitat perquè s'asemblen a l'objecte real.

- Altres representen la realitat segons un codi convencional i arbitrari, és a dir, que entre el significat -idea, concepte- i el significant -diversos tipus d'imatge: acústica, tàctil, visual...- no existeix cap tipus de relació de semblança. Per exemple, l'animal ànec i la paraula que el representa no s'assemblen en res. Per això, cada llengua representa l'ànec amb una paraula diferent. Els elements que representen la realitat segons un codi convencional i arbitrari s'anomenen signes. Els signes lingüístics del llenguatge oral i escrit, els signes d'una determinada ideologia, el signes del Morse, el signes del llenguatge dels sords o els signes del llenguatge Braille, són exemples d'aquest tipus.

La funció representativa o capacitat per comprendre i manipular representacions (simbols i signes) repercuteix de forma significativa sobre l'activitat humana, perquè permet:

- Substituir la realitat (persones, objectes, éssers vius...) per representacions d'aquesta.

- Operar mentalment sobre la realitat de forma mediada, és a dir, mitjançant el signe o el simbol que la representa.

- Representar i retenir (emmagatzemar a la memòria) a nivell intern representacions d'un mateix, dels altres i dels objectes, i evocar-les i represen- 


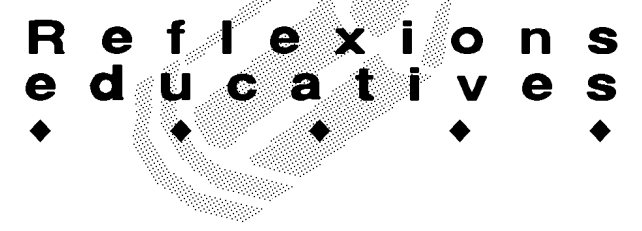

tar-les a nivel extern (exterioritzar-les) de forma objectiva, mitjançant diferents llenguatges expressius.

Com s'apuntava abans, aquesta activitat representativa també es present al moment d'expressivitat motriu que els infants fan dins la sala de psicomotricitat, tot $i$ que amb diferències qualitatives segons el nivell de desenvolupament de les capacitats representatives dels nens i nenes que hi participen. També s'ha dit abans que aquesta activitat representativa espontània durant l'activitat motriu no és directament observable ni, possiblement, es doni gaire conscientment. Per aquestes raons, la proposta del treball psicomotriu a la sala de psicomotricitat ha d'incloure un moment específic de representació de l'acció motriu que s'ha fet durant el primer moment. Es tracta de posar a l'abast dels infants un espai i un moment per distanciar-se de l'acció i per reflexionar i interioritzar aquesta acció mitjançant l'ús de substituts representatius (Esquema 2). És un moment cognitiu on els infants pensen i exterioritzen el seu pensament mitjançant produccions simbòliques (dibuixos, explicacions verbals o escrites, reconeixement d'imatges) de l'activitat viscuda al primer moment.

El model de pràctica psicomotriu de $\mathrm{B}$. Aucutourier vincula aquest segon moment amb la representació simbòlica dels aspectes emocionals i afectius (pors, angoixes, goig, plaer...) viscuts al moment d'expressivitat motriu i entén que el treball de les representacions, en tant que afavoreix l'expressió de les emocions negatives, ajuda l'infant a distanciar-se d'elles i dels objectes que les provoquen. Dins d'aquest marc, l'acció educativa recau bàsicament sobre els aspectes emocionals $i$ afectius.

A nosaltres, sense descartar la vessant emocional i afectiva de l'activitat representativa, en interessa, també i sobretot, la vessant cognitiva, ja que ens sembla una bona via per afavorir la construcció de les nocions corporals (esquema coroporal), motrius (accions corporals), espacials (orientació i estructuració espacial) i temporals (orientació i estructuració temporal) i el desenvolupament de les mateixes capacitats representatives i per estudiar la relació entre el treball psicomotriu a la sala i l'evolució i desenvolupament d'aquestes nocions. En conseqüència, tot i que partim de la proposta de B. Aucouturier pel que fa als dos grans moments de la sessió de psicomotricitat, no ens limitem a treballar només els aspectes emocionals i afectius. Pensem que aquesta estructura del treball psicomotriu és vàlida per al treball dels aspectes cognitius de la motricidad, és a dir:

- D'una banda, per a la construcció de les nociones corporals, motrius, espacials i temporals. L'activitat motriu (moure's) és la base de la construcció del coneixement corporal (conèixer) que l'infant fa i reté de forma simbòlica (amb substituts simbòlics de l'acció i del cos).

- D’altra banda, per al desenvolupament de les capacitats simbòliques. Entre l'activitat motriu i l'activitat represensentativa les relacions son mútues i bidireccionals: el desenvolupament de les capacitats representatives influeix en la possibilitat de representar el cos i el movimient corporal i, inversament, l'activitat mental de representar el cos i el movimient corporal influeix en el desenvolupament de la mateixa capacitat representativa.

\section{Justificació curricular}

Des de la nostra concepció, entenem que l'educació psicomotriu ha d'incidir no tan sols en el desenvo-

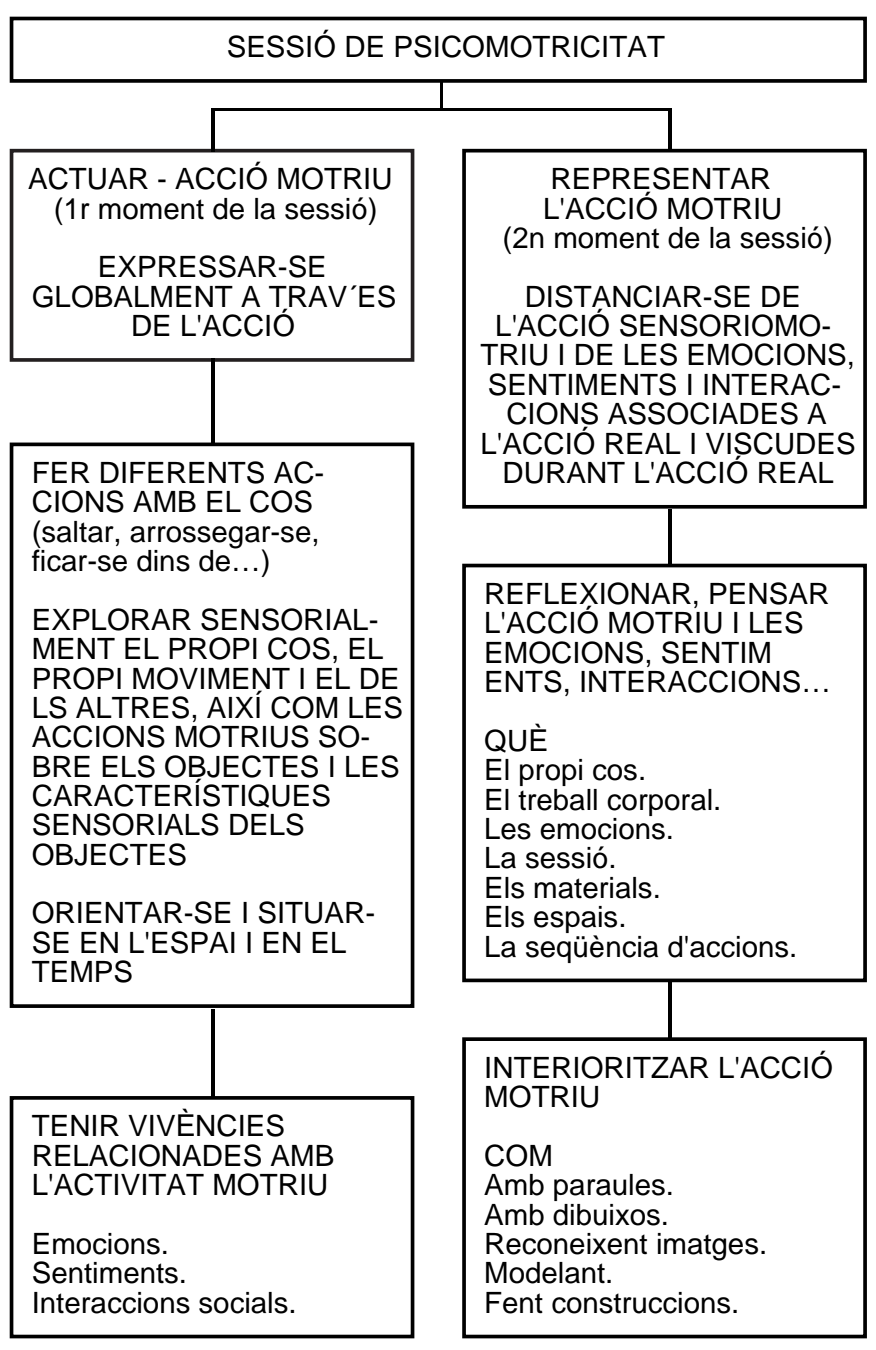

Esquema 2. Etapes en l'acció motriu 


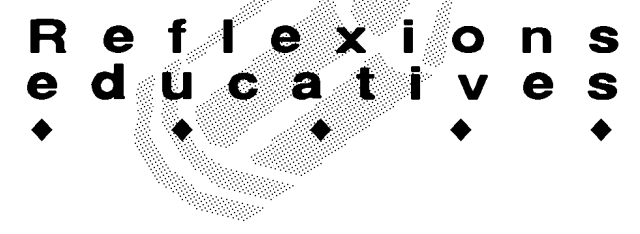

lupament de l'acció pròpiament motriu, sinó també sobre el desenvolupament de la representació de l'acció motriu i sobre la construcció del coneixement motriu i corporal.

En sintonia amb el currículum d'Educació Infantil i primer cicle de Primària, ens proposem recercar com es pot promoure i afavorir educativament el desenvolupament i el domini progressiu de l'activitat representativa, que és un dels objectius generals de l'etapa d'educació infantil i de l'educació psicomotriu i l'eina básica per a la construcció del coneixement.

Entre els objectius generals del cicle de llar d'Infants se cita de manera explícita que els nens i nenes, en acabar aquest període, hauran de ser capaços de "representar objectes i accions de la vida quotidiana mitjançant el joc simbòlic i els diferents llenguatges".

Entre els objectius generals del cicle de Parvulari es diu que, al finalitzar aquest període, els infants hauran de ser capaços de "representar-se mentalment la realitat, evocar-la i interpretar diferents representacions simbòliques (signes i símbols)".

Entre els objectius de l'àrea "descoberta d'un mateix" el currículum d'Educació Infantil explicita com a objectius relacionats amb els aspectes representatius els següents: "...elaborar la primera representació mental de l'espai en el qual s'integrin les propietats topològiques"; "elaborar la primera representació mental del temps a partir de les propies vivències". Pensem que també hi hauria de figurar com a objectiu elaborar la primera representació del cos i del moviment corporal.

En referència als objectius de l'Educació Psicomotriu, el currículum d'Educació Infantil diu: "L'activitat psicomotriu ha de quedar recollida al nivell de representació simbolica que el nen és capaç de fer. Projectant i expressant les activitats efectuades, el nen plasma la captació que té de l'espai, l'ordre de les activitats... La representació han de poder-la expressar mitjançant els diferents llenguatges".

De forma sintètica, a la recerca que estem fent:

- Estudiem el pas del moviment (acte motor) a la representació del moviment i la repercussió d'aquesta sobre la construcció del coneixement d'un mateix, de l'entorn natural i social i dels llenguatges en nens i nenes d'edats compresses entre els 3 i els 7-8 anys.

- Ens centrem en l'activitat representativa, és a dir, en la representació de l'acció motriu i d'un mateix mitjançant significants diversos (signes lingüístics del llenguatge oral i escrit, dibuixos, imatges mentals, pictogrames), la funció dels quals és possibilitar que els nens i nenes facin referència a l'acció motriu i tot el que ella implica, i distanciarse de l'acció.
- Contemplem la representació com a element de distanciació, reflexió i interiorització de les accions motrius reals $i$ de les vivències, sentiments $i$ emocions que han tingut els infants durant la primera part de la sessió (refer-les, pensar-les, prendre'n consciència). Parlar de, dibuixar, reconèixer imatges d'accions, modelar, fer construccions amb fustes són exemples d'activitats representatives de les accions motrius i de les emocions viscudes en el curs d'aquestes accions que afavoreixen la exteriorització de les vivències motrius i corporals i la construcció del coneixement.

- Entenem l'activitat representativa com la capacitat per evocar-representar-reconèixer les accions motrius realitzades i els sentiments i emocions viscudes en relació amb aquestes; els espais per on s'han mogut; els itineraris seguits; la seqüència d'accions fetes; els materials amb què han interactuat durant la primera part de la sessió de psicomotricitat.

\section{Objectius}

- Afavorir l'activitat representativa a partir del treball psicomotor i veure'n l'evolució al llarg d'aquests dos cicles.

- Comparar la capacitat de representació del cos i del moviment en els infants de diferents edats i de diferents nivells de maduració i de desenvolupament (fins i tot, si es donés el cas, nens i nenes amb necessitats educatives especials).

- Identificar nens i/o nenes amb dificultats en els aspectes representatius i detectar les seves causes.

- Estudiar l'evolució de la representació del propi cos i del moviment i descobrir si la representació sistemàtica de l'activitat motriu espontània incideix favorablement sobre la construcció de les nocions corporals, motrius, espacials i temporals.

- Potenciar els aspectes representatius vinculats als aprenentatges de les tres àrees curriculars d'Educació Infantil, i en especial, als processos de construcció del coneixement motriu i corporal.

\section{Procediment}

- Treballem sobre una mostra de nens i nenes d'escoles públiques i concertades de Tarragona i Reus, d'edats compreses entre 3 i 8 anys. Els mestres que participen en la recerca han triat a l'atzar 4 nens/es del grup classe, per tal d'observarlos i fer-ne un seguiment exhaustiu. Això ens dóna una mostra de 22 infants. 


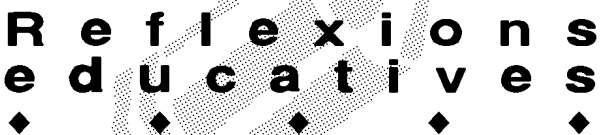

- Totes les sessions de psicomotricitat es fan des del model esmentat abans: Ritual d'entrada, moment d'activitat espontània (activitat motriu i joc simbòlic), moment de representació i ritual de comiat

- L'observació i seguiment dels infants de la mostra es fa a partir d'uns instruments elaborats pel grup de treball, que, òbviament, no podem inclou-re per manca d'espai: Graella per fer l'observació de l'activitat motriu espontània, pauta per fer l'activitat representativa i pauta per fer l'anàlisi de l'activitat representativa. De manera periòdica es filmen les sessions.

- Mensualment el grup de treball es reuneix per tal d'analitzar l'activitat representativa dels nens $\mathrm{i}$ nenes de la mostra (les seves produccions) i identificar si s'han donat canvis significatius en les seves capacitats representatives o si persisteixen les mateixes dificultats pel que fa a la representació del primer moment de la sessió. Així mateix, s'analitza i es valora la relació entre els progressos en les capacitats representatives i el progressos en la construcció del coneixement psicomotor.

\section{Estat actual de la recerca}

Durant el curs 2000-01 es va elaborar el marc teòric de la recerca i els instruments per fer l'observació i el seguiment de l'activitat representativa. Es van fer dues aplicacions pilot dels intruments per tal de comprovar la seva utilitat, i a partir dels resultats, es van fer algunes modificacions.

El primer trimestre del curs 2001-02 hem seguit refent, millorant i completant tots els instruments de la recerca per acabar-los d'ajustar als objectius que pretenem en aquest estudi.

Al mes de gener de 2002 hem iniciat l'aplicació sistemàtica dels instruments en les sessions de psicomotricitat sobre els nens i nenes de les diferents escoles implicades en el projecte.

De moment encara no estem en condicions de donar informació sobre els resultats de la recerca, cosa que farem més endavant quan en puguem disposar.

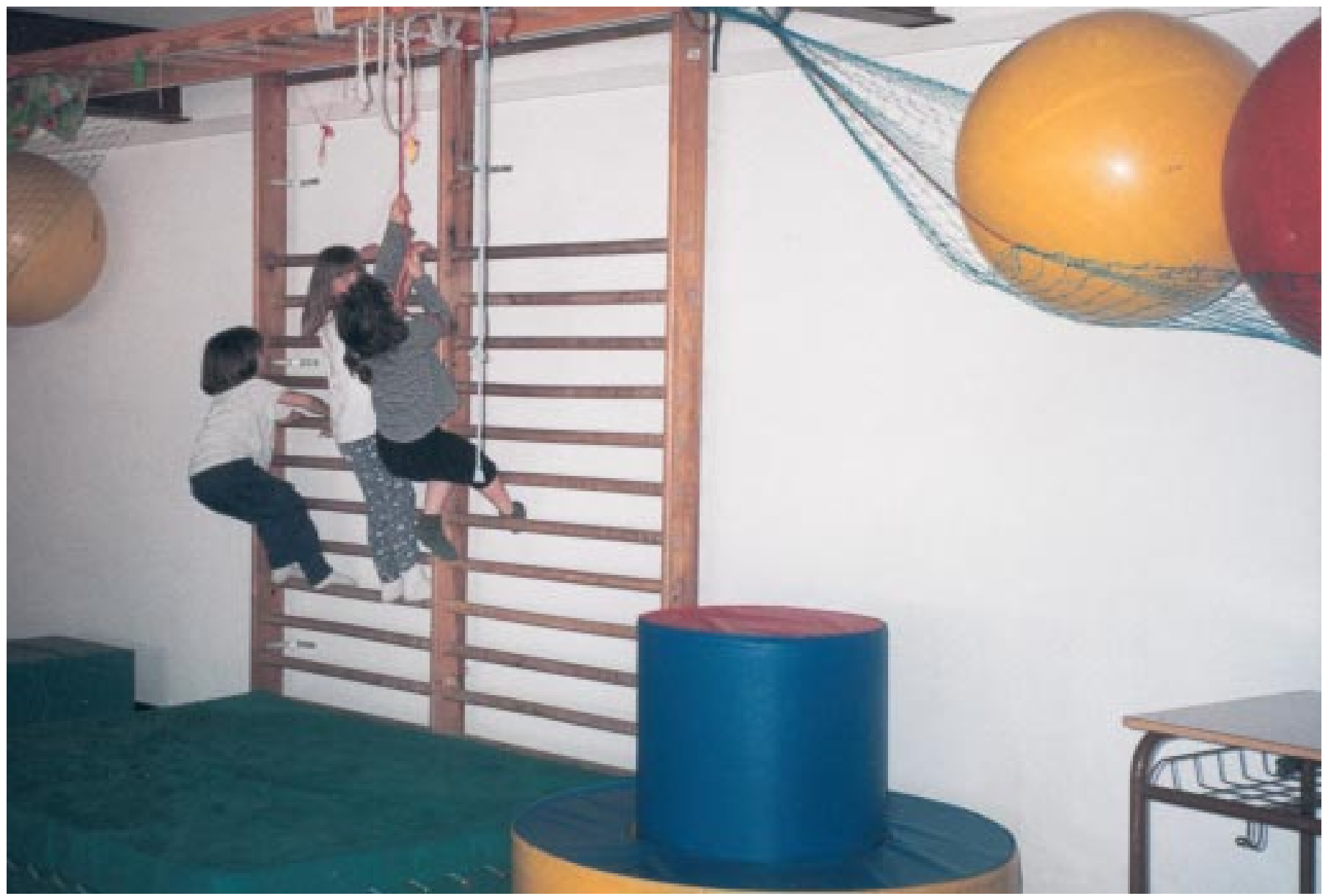

